\title{
A case of Brugada syndrome presenting with fatal cardiac arrhythmia in a 3-year-old Sri Lankan child
}

\section{Navabalasooriyar Pradeep ${ }^{1}$, *Imalke Kankananarachchi ${ }^{2}$, Shehan Perera ${ }^{1}$, Nalin Kitulwatte ${ }^{1}$}

Sri Lanka Journal of Child Health, 2020; 49(2): 180-181

DOI: http://dx.doi.org/10.4038/sljch.v49i2.8969

(Key words: Brugada syndrome, channelopathy, arrhythmia, fatal, isoprenaline)

\section{Introduction}

Brugada syndrome (BS) is an autosomal dominant inherited channelopathy which causes fatal ventricular arrhythmias and sudden cardiac death ${ }^{1}$. It usually presents after adolescence and is rarely seen in the paediatric age group ${ }^{2}$. BS is known to precipitate with febrile illness in children ${ }^{2}$. Here we report a 3-year-old child with Brugada syndrome presenting with fatal cardiac arrhythmia in the absence of any precipitating event.

\section{Case report}

A 3 year old previously healthy boy presented to the emergency treatment unit (ETU) with sudden onset of unresponsiveness of a few hours duration. On arrival, he was in a state of cardiac arrest and immediate cardiopulmonary resuscitation (CPR) was commenced. Electrocardiogram (ECG) revealed monomorphic ventricular tachycardia and he was treated with direct cardioversion, which restored the sinus rhythm after a down time of 15 minutes.

There was no history of preceding febrile illness, head trauma or poisoning. Family history was negative for sudden infant death syndrome or sudden cardiac arrest. Following 8 hours of admission to the intensive care unit, he developed another monomorphic ventricular tachycardia which reverted to sinus rhythm with direct cardioversion. His basic haematological and biochemical parameters, including serum calcium, were normal. 2D echocardiogram revealed a structurally normal heart. His repeat ECG showed characteristic coved ST elevation greater than $2 \mathrm{~mm}$ in precordial leads V2 and V3 (Figure 1).

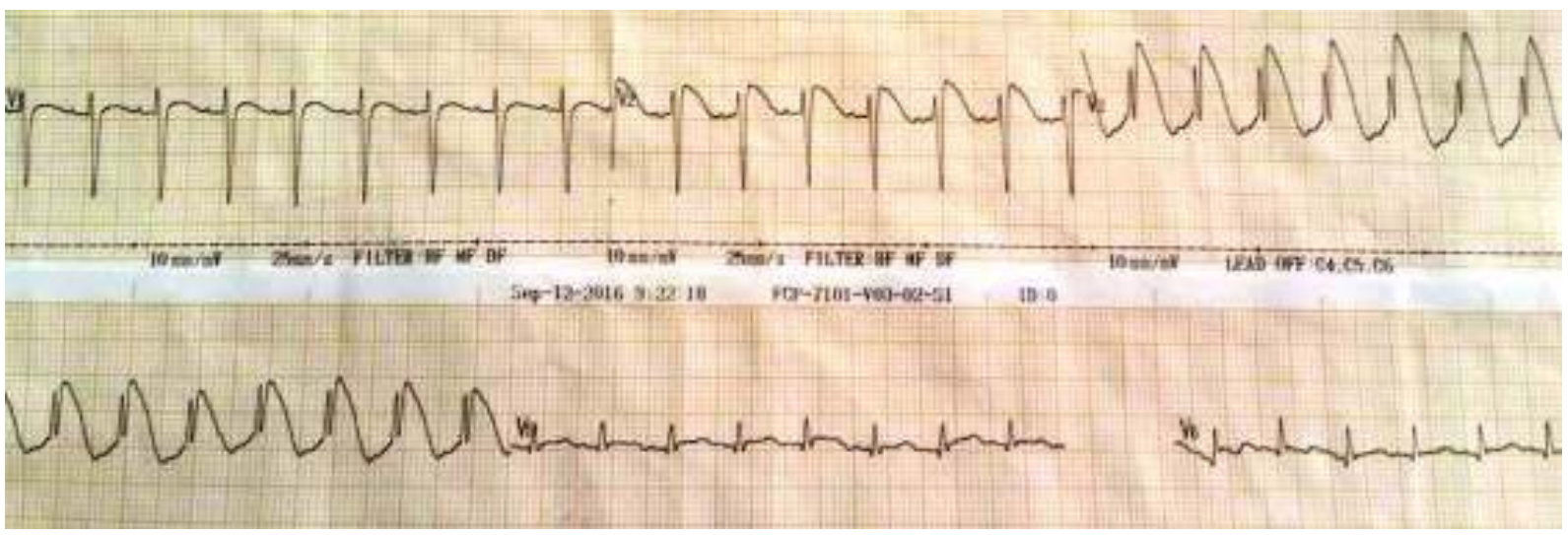

Figure 1: ECG showing coved ST elevation in V2 and V3 leads

$\overline{{ }^{1} \text { Lady Ridgeway Hospital, Colombo, Sri Lanka, }}$

${ }^{2}$ Faculty of Medicine, University of Ruhuna, Sri

Lanka,

*Correspondence: imalke462@gmail.com

orcid.org/ 0000-0002-9351-2966

(Received on 08 August 2018: Accepted after revision on 28 September 2018)

The authors declare that there are no conflicts of interest

Personal funding was used for the project.

Open Access Article published under the Creative

Commons Attribution CC-BY (cc) (P) License
The diagnosis of Brugada syndrome was made and he was started on isoprenaline. Genetic testing was not performed due to economic constraints. An age matched implantable cardioverter defibrillator (ICD) was not available for insertion. He succumbed after five days due multi-organ failure as a result of ischaemic insult following prolonged cardiac arrest. ECG of family members revealed no Brugada pattern.

\section{Discussion}

BS is relatively a new entity described in 1992 by Professor Pedro Brugada ${ }^{3}$. Even though the condition is rare in children, BS was first described in a 3-year-old Polish child with a background 
history of sudden cardiac deaths in the family ${ }^{3}$. The condition is common among young Asian males ${ }^{4}$. The prevalence of the condition varies between $1: 2000$ to $1: 5000^{4,5}$. Moreover, $10-20 \%$ of sudden cardiac deaths in children are secondary to inherited channelopathies including $\mathrm{BS}^{4}$. The gene responsible for $\mathrm{BS}$ is identified as SCN5A and number of mutations have been identified in the gene since the discovery of the condition ${ }^{6}$.

Clinical presentation of BS varies from the asymptomatic stage to sudden cardiac death due to ventricular fibrillation or ventricular tachycardia. In between these two extremes, some children can have syncope or palpitations ${ }^{2}$. However, in this child, prior to this presentation, there were no such episodes.

The diagnosis of $\mathrm{BS}$ is made based on the characteristic ST segment elevation patterns seen in right precordial leads. There are 3 patterns of ST elevations is BS viz. coved type, $>1 \mathrm{~mm}$ saddle back elevation and $<1 \mathrm{~mm}$ saddle back elevation ${ }^{3}$. In this child, coved ST elevation was noted in the V2 and V3 leads. In addition, short PR interval, short QT interval and narrow QRS complexes were more common among children with $\mathrm{BS}^{7}$.

Treatment of the condition consists of lifestyle modifications, antiarrhythmic treatment and $\mathrm{ICD}^{2}$. It is important to manage febrile illness efficiently in order to prevent cardiac arrhythmias and certain drugs such as certain anti epileptics, anaesthetic agents and antipsychotics should be withheld from patients with BS. Furthermore, patients should refrain from using alcohol, cocaine and cannabis ${ }^{7}$.

The drug of choice in electrical storms of BS is isoprenaline and in refractory cases, quinidine is added ${ }^{8}$. In this child, though the cardiac rhythm was normalizing with drug therapy, he was in multiorgan failure by the time he presented with cardiac arrest. ICD is the treatment of choice of patients with poor response to medical therapy ${ }^{2}$. Family screening is an essential component in the management and none of the family members of this child had ECG abnormalities. Those who are detected with family screening should be educated on lifestyle modifications and preventive drug therapy ${ }^{8}$.

\section{References}

1. Meregalli PG, Wilde AAM., Tan H.L. Pathophysiological mechanisms of Brugada syndrome: depolarization disorder, repolarization disorder, or more? Cardiovascular Research 2005; 67: 367-78.

https://doi.org/10.1016/j.cardiores.2005.03

.005

PMid: 15913579

2. Behere SP, Weindling SN. Brugada syndrome in children-Stepping into unchartered territory. Annals of Pediatric Cardiology 2017; 10(3):248.

https://doi.org/10.4103/apc.APC_49_17

PMid: 28928611 PMCid: PMC55 $54 \overline{9} 36$

3. Brugada P, Brugada J. Right bundle branch block, persistent ST segment elevation and sudden cardiac death: A distinct clinical and electrocardiographic syndrome. A multicentre report. Journal of the American College of Cardiology 1992; 20:1391-6. https://doi.org/10.1016/07351097(92)9025 3-J

4. Triedman JK. Brugada and short QT syndromes. Pacing and Clinical Electrophysiology 2009; 32(Suppl 2): S58-62.

https://doi.org/10.1111/j.15408159.2009.0 2386.x

PMid: 19602164

5. Jellins J, Milanovic M, Taitz DJ, Wan SH, Yam PW. Brugada syndrome. Hong Kong Medical Journal 2013; 19:159-67.

PMid: 23535677

6. Chen Q, Kirsch GE, Zhang D, Brugada R, Brugada J, Brugada $\mathrm{P}$, et al. Genetic basis and molecular mechanism for idiopathic ventricular fibrillation. Nature 1998; 392: 293-6.

https://doi.org/10.1038/32675

PMid: 9521325

7. Probst V, Denjoy I, Meregalli PG, Amirault JC, Sacher F, Mansourati J, et al. Clinical aspects and prognosis of Brugada syndrome in children. Circulation 2007; 115:2042

https://doi.org/10.1161/CIRCULATIONA HA.106.664219

PMid: 17404158

8. Veerakul G, Nademanee K. Treatment of electrical storms in Brugada syndrome. Journal of Arrhythmia 2013; 29(2):117-24. https://doi.org/10.1016/j.joa.2013.02.003 